\title{
Relation between pathological grading and lung fibre concentration in a patient with asbestosis
}

\author{
B GYLSETH, V SKAUG \\ From the Institute of Occupational Health, Oslo, Norway
}

ABSTRACT The fibre concentration and extent and severity of fibrosis have been analysed in 48 specimens from the left lung of a patient with asbestosis. Two different methods of fibre analysis were used. The results obtained by transmission electron microscopy were 2-2.5 times higher thari those obtained by scanning electron microscopy. Low temperature ashed samples showed on average twice the number of fibres obtained after wet digestion of the samples. The transmission electron microscope detected considerably shorter fibres than the scanning electron microscope. Low temperature ashing produced also shorter fibres compared with the wet digestion procedure. A statistically significant correlation between fibre concentration and the grade of fibrosis was found only for low temperature ashed samples analysed in the transmission electron microscope. When dividing the lung into nine anatomical compartments and pooling the grade of fibrosis and the fibre concentration data within each compartment, an even better correlation was obtained.

It is generally agreed that progressive asbestosis is caused by heavy asbestos exposure which is reflected by a high fibre concentration in the lung tissue. ${ }^{1}$ The pathogenesis of this disease entails incomplete or complete phagocytosis, macrophage activation, and subsequent liberation of mediators of the inflammatory response. At a later stage fibrosis develops in the respiratory bronchioles and then extends along the peripheral airways and into the adjacent lung parenchyma.

It has also been agreed that asbestosis is generally more severe in the lower lobes ${ }^{2}$ whereas the fibre concentration is higher in the upper lobes. ${ }^{34}$ Some of these variations may be due to factors inherent in tissue sampling and in analytical procedures. It has been unequivocally established that the fibre concentration may vary five to tenfold from one site to another within the lung. ${ }^{5}{ }^{6}$ Interlaboratory exchanges of lung tissue samples have shown that laboratories are reasonably consistent in the application of their own method and that estimates of fibre content in a given case or set of cases may be reliably compared with past data published by that laboratory. Owing to several factors, ${ }^{7}$ however there are pronounced variations in the results from different laboratories.

Questions raised include whether such complex reactions are related to fibre type, dimensions, surface area, number, or mass in the tissue ${ }^{8}$ Limitations such

Accepted 10 March 1986 as detecting the small fibres, interference of other minerals in the lung, and inherent variation in fibre number from different sites in the lung interfere witho the results and should be further elucidated before final conclusions are drawn.

We have analysed 48 tissue specimens using wet digestion and dry ashing of tissue samples followed by scanning and transmission electron microscopical analysis. Adjacent tissue specimens have been subjected to detailed histopathological evaluation. In the present study we have tried to clarify the methodological problems connected with: (1) the analysis of fibres in lung tissue samples; (2) the variation in fibre content from different sites in the lung; and (3) the relation between fibre content and the grade (severity $x$ extent) of pulmonary fibrosis present.

\section{Material and methods}

\section{TISSUE SPECIMENS}

Lungs were obtained at necropsy from a 72 year old man who had been occupationally exposed to asbestos from 1941 to 1974 in an asbestos cement factory. The diagnosis at necropsy was myelomatosis and light/moderate asbestosis. The use of asbestos and the exposure conditions in the factory have already been described. ${ }^{9}$

The lungs were fixed by inflation according to standard procedures and a sagittal slice of the left lung, about $1.5 \mathrm{~cm}$ thick, was cut. Forty eight specimens 


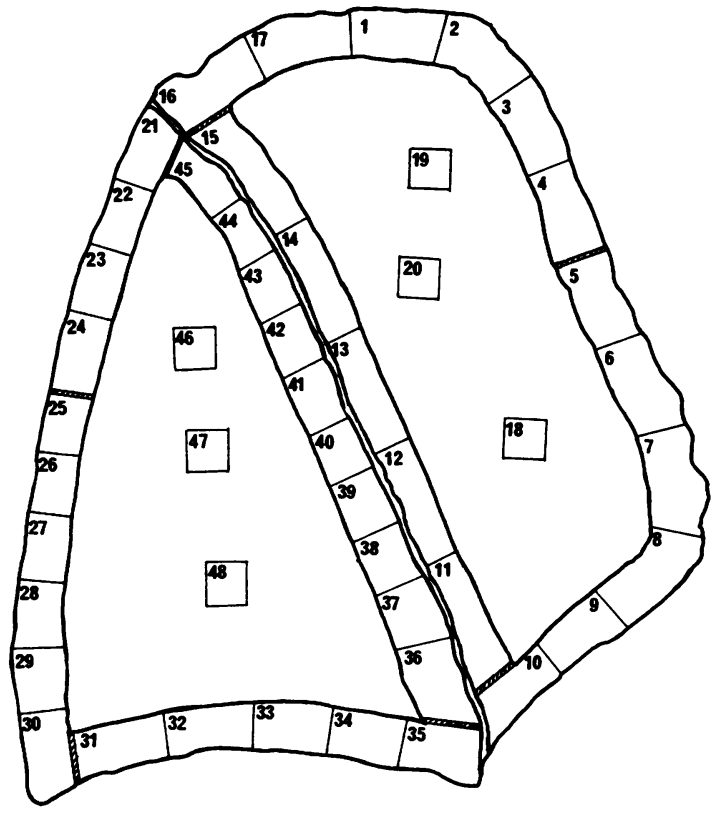

Fig 1 Sampling sites of 48 tissue specimens in lung slice. Borders of anatomical compartments indicated by hatched areas.

were sampled from this slice as shown in fig 1. Each specimen, about $2 \times 1.5 \times 1.5 \mathrm{~cm}$, was cut horizontally into two equal pieces, one for fibre analysis and one for histopathological examination.

\section{HISTOPATHOLOGICAL EXAMINATION}

The lung tissue samples were embedded in paraplast and $5 \mu \mathrm{m}$ sections were stained with haematoxylinphloxine-safran. They were read blind by one experienced pathologist (VS), and each slide was classified according to the proposed asbestosis grading scheme published by the Pneumoconiosis Committee of the College of American Pathologists and the National Institute for Occupational Safety and Health. ${ }^{10}$ Individual recordings of severity and extent of fibrosis were made and the grade of fibrosis calculated (severity $\times$ extent). The grading thus obtained was compared with the fibre number as analysed in the adjacent tissue by electron microscopy.

\section{FIBRE ANALYSIS}

Tissue specimens for analysis were cut into two equal pieces, one of which was subjected to sodium hypochlorite $(\mathrm{NaOCl})$; after complete digestion the washed residue was oxidised at $350^{\circ} \mathrm{C}$ in an oxygen atmosphere for 24 hours. ${ }^{11}$ The other piece was cut into smaller pieces and an appropriate amount was dried to constant weight at $80^{\circ} \mathrm{C}$. After dry weight was obtained, about $30-50 \mathrm{mg}$ of dried tissue was ashed for two to four hours in a low temperature plasma asher (LTA). Each residue from the ashing procedures was suspended in $0.5 \mathrm{M}$ of hydrochloric acid with added alcohol and treated for five minutes in an ultrasonic bath. Ninety six samples were then filtered on to Nuclepore membranes with pore size $\mathbf{0 . 2}$ $\mu \mathrm{m}$ and diameter $47 \mathrm{~mm}$.

A piece of each filter was attached to a carbon stub by carbon glue and coated with gold for scanning electron microscopy (SEM). Another piece of each filter was coated with carbon, placed on an electron microscope grid, and transferred to a beaker containing a polyurethane sponge soaked in chloroform. After 24 hours the Nuclepore membrane had dissolved and the specimen was ready for transmission electron microscopy (TEM). The following four categories of samples, comprising in all 192 specimens, were subjected to total fibre concentration and fibre length determination:

SEM of $\mathrm{NaOCl}$ digested tissue,

SEM of LTA ashed tissue,

TEM of $\mathrm{NaOCl}$ digested tissue, and

TEM of LTA ashed tissue.

In addition, the concentration and length of asbestos bodies were determined in the two SEM specimens. For SEM, $4500 \times$ magnification was used and either 200 fields or 100 fibres were counted, whichever came first. For TEM, the magnification was $5000 \times$ and in all samples 50-100 fibres were analysed.

\section{STATISTICAL METHODS}

Plotting of the fibre counts on a log-probability paper according to the method published by NIOSH ${ }^{12}$ gave a straight line for all sample categories indicating a log-normal distribution of the results. Parametric statistical tests have been used to calculate the probability levels (Student's $t$ test) and correlation coefficients (Pearson's).

\section{Results}

COMPARISON OF METHODS FOR FIBRE ANALYSIS Table 1 gives the overall fibre counts and the grades of fibrosis. As shown, the TEM counts are on average 2-2.5 times higher than the SEM counts. Counts for the low temperature ashed samples are on average about twice as high as the corresponding numbers for wet digested samples for both SEM and TEM analysis.

In table 2 the length distribution of uncoated asbestos fibres is given in seven different size categories. It is clear that short fibres are easier to detect in the TEM than the SEM. Another striking feature is the difference between the LTA and the $\mathrm{NaOCl}$ processed samples; $\mathrm{NaOCl}$ produces the longest fibres. 
Table 1 Asbestos fibre counts, asbestos body counts, and grading of fibrosis for 48 tissue samples from the same lung.

Fibre numbers are given in $10^{6}$ and bodies in $10^{4}$ per gram of dried tissue

\begin{tabular}{|c|c|c|c|c|c|c|c|}
\hline \multirow[b]{3}{*}{ Sample No } & \multicolumn{3}{|c|}{ Low temperature ashing } & \multicolumn{3}{|c|}{ Wet digestion } & \\
\hline & \multicolumn{2}{|l|}{ Fibres } & \multirow{2}{*}{$\frac{\text { Bodies }}{S E M}$} & \multicolumn{2}{|l|}{ Fibres } & \multirow{2}{*}{$\frac{\text { Bodies }}{\text { SEM }}$} & \multirow{2}{*}{$\begin{array}{l}\text { Fibrosis grade } \\
\text { (extent } \times \text { severity) }\end{array}$} \\
\hline & $S E M$ & $T E M$ & & $S E M$ & $T E M$ & & \\
\hline 1 & 121 & 190 & 40 & 57 & 243 & 80 & 1 \\
\hline 2 & 89 & 188 & 70 & 143 & 303 & 280 & $t$ \\
\hline 3 & 96 & 186 & 50 & $*$ & $*$ & $*$ & 1 \\
\hline 4 & 280 & 682 & 140 & 67 & * & 240 & 4 \\
\hline 5 & 143 & 612 & 50 & $*$ & * & $*$ & 4 \\
\hline 6 & 126 & 434 & 110 & 16 & 56 & 50 & 6 \\
\hline 7 & 121 & 333 & 50 & 12 & 36 & 30 & 9 \\
\hline 8 & 142 & 388 & 50 & 181 & 199 & 380 & 6 \\
\hline 9 & 130 & 338 & 120 & 30 & 60 & 30 & 6 \\
\hline 10 & 83 & 242 & 80 & 28 & 63 & 70 & 4 \\
\hline 11 & 88 & 189 & 80 & 19 & 36 & 60 & 4 \\
\hline 12 & 216 & 452 & 120 & 51 & 83 & 220 & 4 \\
\hline 13 & 158 & 428 & 90 & 41 & 75 & 110 & 6 \\
\hline 14 & 128 & 397 & 80 & 43 & 96 & 120 & 4 \\
\hline 15 & 143 & 255 & 50 & 30 & 74 & 90 & 1 \\
\hline 16 & 198 & 481 & 70 & 35 & 98 & 150 & 0 \\
\hline 17 & 80 & 194 & 30 & 56 & 89 & 110 & 6 \\
\hline 18 & 171 & 310 & 100 & 35 & 82 & 130 & 1 \\
\hline 19 & 235 & 398 & 160 & 34 & 92 & 100 & 1 \\
\hline 20 & 104 & 170 & 10 & 27 & 110 & 60 & 6 \\
\hline 21 & 136 & 251 & 40 & 13 & 60 & 20 & 3 \\
\hline 22 & 89 & 140 & 30 & 18 & 64 & 40 & 2 \\
\hline 23 & 75 & 136 & 30 & 21 & 70 & 60 & 1 \\
\hline 24 & 105 & 274 & 70 & 67 & 185 & 70 & 1 \\
\hline 25 & 110 & 265 & 90 & 39 & 101 & 90 & 0 \\
\hline 26 & 108 & 440 & 80 & 36 & 119 & 80 & 0 \\
\hline 27 & 70 & 224 & 30 & 34 & 94 & 70 & 2 \\
\hline 28 & 90 & 252 & 70 & 45 & 186 & 30 & 1 \\
\hline 29 & 44 & 131 & 10 & 38 & 107 & 70 & 0 \\
\hline 30 & 107 & 141 & 70 & 52 & 133 & 50 & 0 \\
\hline 31 & 73 & 125 & 70 & 50 & 99 & 130 & 1 \\
\hline 32 & 37 & 70 & 10 & 37 & 36 & 80 & 0 \\
\hline 33 & 59 & 103 & 30 & 90 & 371 & 20 & 0 \\
\hline 34 & 88 & 104 & 120 & 78 & 144 & 40 & 0 \\
\hline 35 & 87 & 113 & 20 & 30 & 74 & 20 & 0 \\
\hline 36 & 69 & 138 & 100 & 39 & 84 & 50 & 1 \\
\hline 37 & 258 & 120 & 150 & 55 & 127 & 30 & 0 \\
\hline 38 & 146 & 245 & 50 & 53 & 84 & 110 & 2 \\
\hline 39 & 127 & 327 & 130 & 64 & 190 & 60 & 0 \\
\hline 40 & 104 & 344 & 80 & 63 & 137 & 60 & 2 \\
\hline 41 & 61 & 458 & 70 & 64 & 209 & 60 & 1 \\
\hline 42 & 139 & 252 & 50 & 78 & 197 & 160 & 6 \\
\hline 43 & 186 & 267 & 140 & 354 & 546 & 350 & 4 \\
\hline 44 & 117 & 232 & 110 & 48 & 123 & 70 & 2 \\
\hline 45 & 128 & 276 & 390 & 263 & 558 & 670 & 1 \\
\hline 46 & 105 & 158 & 80 & 47 & 110 & 80 & 1 \\
\hline 47 & 213 & 400 & 150 & 197 & 430 & 30 & 1 \\
\hline 48 & 60 & 94 & 20 & 57 & 115 & 20 & 1 \\
\hline Geometric mean & 111 & 236 & 60 & 48 & 121 & 70 & \\
\hline
\end{tabular}

*Tissue sample too small.

†Impossible to evaluate.

Table 2 Length distribution (\%) of uncoated fibres as measured by four different techniques

\begin{tabular}{|c|c|c|c|c|c|c|c|c|}
\hline \multirow[b]{2}{*}{ Method } & \multirow[b]{2}{*}{ No of fibres counted } & \multicolumn{7}{|c|}{ Length ( $\mu \mathrm{m})$} \\
\hline & & $<1$ & $>1<2$ & $>2<5$ & $>5<10$ & $>10<20$ & $>20<50$ & $>50$ \\
\hline $\begin{array}{l}\text { SEM/LTA } \\
\text { SEM/NaOC1 } \\
\text { TEM/LTA } \\
\text { TEM/NaOCl }\end{array}$ & $\begin{array}{l}4800 \\
4600 \\
3295 \\
2479\end{array}$ & $\begin{array}{l}0 \\
0 \\
6 \cdot 6 \\
0 \cdot 2\end{array}$ & $\begin{array}{c}0 \cdot 2 \\
0 \\
21 \cdot 7 \\
4 \cdot 1\end{array}$ & $\begin{array}{r}3 \cdot 7 \\
0.7 \\
51 \cdot 1 \\
34 \cdot 8\end{array}$ & $\begin{array}{l}20 \cdot 4 \\
13 \cdot 4 \\
16 \cdot 7 \\
35 \cdot 5\end{array}$ & $\begin{array}{r}46 \cdot 2 \\
37 \cdot 5 \\
3 \cdot 7 \\
18 \cdot 4\end{array}$ & $\begin{array}{r}28 \cdot 6 \\
41 \cdot 2 \\
0 \cdot 4 \\
7 \cdot 1\end{array}$ & $\begin{array}{l}0 \cdot 8 \\
7 \cdot 3 \\
0 \\
0\end{array}$ \\
\hline
\end{tabular}

SEM = Scanning electron microscopy.

LTA $=$ Low temperature plasma asher.

$\mathrm{NaOCl}=$ Sodium hypochlorite.

$\mathrm{TEM}=$ Transmission electron microscopy. 
Table 3 Length distribution (\%) of coated fibres as measured by scanning electron microscopy after two different methods of preparation

\begin{tabular}{lllllllr}
\hline \multirow{2}{*}{ Method } & \multirow{2}{l}{ Length $(\mu \mathrm{m})$} & & & \\
\cline { 2 - 7 } & No of fibres counted & $>1<2$ & $>2<5$ & $>5<10$ & $>10<20$ & $>20<50$ & $>50$ \\
\hline SEM/LTA & 2197 & $0 \cdot 1$ & $3 \cdot 3$ & $24 \cdot 0$ & $39 \cdot 8$ & $30 \cdot 4$ & $2 \cdot 6$ \\
SEM/NaOC1 & 2078 & 0 & $1 \cdot 2$ & $12 \cdot 2$ & 27.9 & $43 \cdot 4$ & $15 \cdot 3$ \\
\hline
\end{tabular}

SEM, LTA, $\mathrm{NaOC} 1$ see table 2.

This difference is also apparent for the coated fibres (table 3).

Comparison of the different preparation and analytical methods used for coated and uncoated fibres showed noticeable differences. When comparing the two analytical methods using specimens prepared by the same ashing technique, the correlation coefficient for SEM/LTA $v$ TEM/LTA was $r=0.65$. The corresponding figure for $\mathrm{SEM} / \mathrm{NaOC} 1 v \mathrm{TEM} / \mathrm{NaOC} 1$ was $r=0 \cdot 88$.

The highest correlation coefficient between uncoated and coated fibres was found for the SEM/LTA method $(r=0.64)$. The corresponding number for $\mathrm{SEM} / \mathrm{NaOCl}$ was $\mathrm{r}=\mathbf{0} \cdot \mathbf{5 2}$. Comparison of uncoated fibres obtained by TEM/LTA and the corresponding number of coated fibres obtained by SEM/LTA gave $r=0.52$. The lowest correlation coefficient found was between uncoated fibres analysed by $\mathrm{TEM} / \mathrm{NaOCl}$ and coated fibres analysed by $\mathrm{SEM} / \mathrm{NaOC1}$ which gave $\mathrm{r}=0.33$.

The consistency between $\mathrm{SEM} / \mathrm{NaOCl}$ and $\mathrm{TEM} / \mathrm{NaOCl}$ is illustrated in fig 2 .

\section{COMPARISON OF PATHOLOGY AND FIBRE}

NUMBER

Initially all four methods were tested for correlation with the extent, severity, and grade of lung fibrosis.

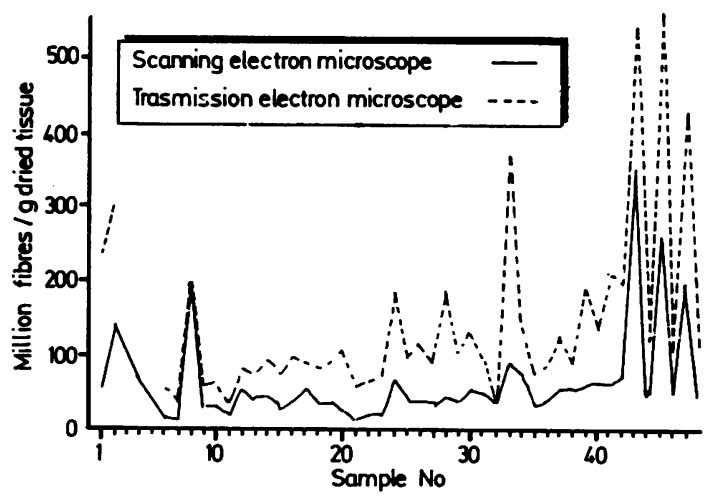

Fig 2 Comparison of results obtained by scanning and transmission electron microscopy for uncoated fibres after wet digestion of the tissue samples.
Table 4 Pooled fibre concentrations from different anatomical compartments of the lung and the corresponding grade of lung fibrosis

\begin{tabular}{lll}
\hline $\begin{array}{l}\text { Anatomical compartment } \\
\text { (sample No) }\end{array}$ & $\begin{array}{l}\text { Geometric mean } \\
\text { fibre concentration }\end{array}$ & $\begin{array}{l}\text { Mean } \\
\text { fibrosis } \\
\text { score }\end{array}$ \\
\hline I (5-10) & $391 \cdot 2$ & $5 \cdot 8$ \\
II(1-4, 16,17) & $320 \cdot 3$ & $2 \cdot 4$ \\
III(21-24) & $200 \cdot 3$ & $1 \cdot 8$ \\
IV(25-29) & $262 \cdot 4$ & $0 \cdot 6$ \\
V(30-35) & $109 \cdot 3$ & $0 \cdot 2$ \\
VI(36-45) & $265 \cdot 9$ & $1 \cdot 9$ \\
VII(11-15) & $344 \cdot 2$ & $3 \cdot 8$ \\
VIII(46-48) & $217 \cdot 3$ & $1 \cdot 0$ \\
IX(18-20) & $292 \cdot 7$ & $2 \cdot 7$ \\
\hline
\end{tabular}

The only series of results that was statistically significantly correlated with the grade of lung fibrosis was that of the TEM/LTA method $(r=0.41$, $\mathrm{p}=0.0044)$. The results from the SEM/LTA method were close to significance $(r=0.25, p=0.0942)$. The lung was further divided into nine anatomical compartments, and the fibre concentration (TEM/LTA) and the scores for grade of fibrosis were pooled. Table 4 gives the results for this score of lung fibrosis and fibre concentration in these nine compartments. The geometric mean of the lung fibre concentration has been compared with the mean grade of lung fibrosis in the same region. A correlation coefficient of $r=0.77$, $p=0.0323$ between these sets of results was found.

\section{Discussion}

In 1973 Ashcroft and Heppleston published a comprehensive report on pulmonary asbestos fibre concentration and its relation to the human pathological reaction. ${ }^{13}$ They showed that progression of the disease from no asbestosis through mild asbestosis to moderate asbestosis is associated with a progressive increase in the fibre content of the lung tissues. Further progression to severe asbestosis is not associated with any additional increase in asbestos fibre concentration. The reasons for the discrepancy in cases with severe asbestosis were discussed, including varying tissue density. They concluded, however, that fibre concentration in particular areas bears no consistent relation to the degree or form of the fibrosis in the advanced disease. 
Similarly, Whitwell et al in 1977 showed that in 23 of 73 patients with mesothelioma some asbestosis was found. ${ }^{4}$ Most of the lungs showing asbestosis contained over three million asbestos fibres per gram of dried tissue and the numbers of asbestos fibres present corresponded roughly with the degree of asbestosis.

Both Ashcroft and Heppleston and Whitwell et al used wet digestion of the samples and counting of fibres in a Fuchs-Rosenthal chamber by phase contrast microscopy. ${ }^{1314}$ It is accepted today that this method has severe limitations with regard to the ability to detect thin fibres. Accordingly the total number of fibres has been underestimated. Despite this underestimation a correlation with the degree of asbestosis was found. The reason for this may be that loss of fibres in the light microscope is constant or that the degree of asbestosis is best correlated to the fibres visible in the light microscope.

Morgan and Holmes made a comparison (light microscopy) of the results obtained from Nottingham gas mask workers exposed to crocidolite ${ }^{15}$ and cases of mesothelioma as analysed by Whitwell et al. ${ }^{14}$ They found that the results published by Whitwell et al were on average five times lower than their own. Jones et al used electron microscopy on cases from the Nottingham gas mask workers ${ }^{16}$ and showed results on average seven times higher than those obtained by Morgan and Holmes. ${ }^{15}$ The data presented by Morgan and Holmes showed that the membrane filter method detects more fibres than the counting chamber technique. The difference between the techniques, however, was constant over the concentration range covered.

In this study we have shown that the TEM gives, on average, results that are 2 to $2 \cdot 5$ higher than the SEM. Counts obtained on low temperature ashed samples are on average twice as high as those obtained on adjacent wet digested samples for both SEM and TEM.

The difference observed between TEM and SEM is obviously caused by the better resolution of the TEM. Furthermore, it is easier to count directly from a TEM screen than from an SEM screen. The difference between low temperature ashed and wet digested samples has no ready explanation. It has previously been shown by Gylseth and Baunan that the drying of tissue before ashing breaks asbestos bodies and long fibres. ${ }^{17}$ This breakage, however, cannot account completely for the difference observed. The remaining difference is probably caused both by loss of fibres during the wet digestion procedure ${ }^{18}$ and by the greater ability to detect fibres, especially the smaller ones, in the low temperature ashed samples. This improved detectability is due to the low temperature ashing producing less interfering background mate- rial compared with wet digestion. ${ }^{19}$ In particular, increasing filter loads have been shown to produce fibre concentration lower than expected, probably due to the shielding effect of remaining debris. ${ }^{20}$ Despite the above mentioned factors, the correlation between SEM and TEM is acceptable for both methods, implying that conversion factors may be established for different laboratories.

Owing to the high fraction of amphibole fibres found, the length distribution is skewed towards higher values compared with length distributions derived from chrysotile fibres. The study also shows that the shorter fibres are more easily seen in the TEM than the SEM, and that the wet digestion procedure saves the longest fibres compared with the dry ashed samples.

The attempt to correlate the grade (extent $\times$ severity) of pulmonary fibrosis and the number of fibres gave a statistically significant correlation between the fibrosis score and the number of fibres analysed by TEM after low temperature ashing followed by SEM analysis after low temperature ashing, which was close to statistical significance. Even better results were obtained by pooling the results from individual tissues of areas of anatomical compartments. This is justifiable since there is large variation in the degree of asbestosis within the lung in general, and also in this case. The results obtained by wet digestion were far from statistically significant for both methods. As expected, there is a reasonable correlation between the uncoated and coated fibre number.

The implications of these results are unclear. If the grade (extent $\times$ severity) of mild lung fibrosis is related to the fibre number, however, the low temperature ashing procedure and TEM analysis seem to be the most sensitive methods. By contrast, the lack of correlation between fibrosis and the number of fibres as analysed after wet digestion may indicate a relation to another dose parameter. It is difficult to compare our study with that of Timbrell $e a^{8}{ }^{8}$ as we have only analysed one lung. It should be borne in mind, however, that our samples and those of Timbrell et al have been analysed by two different methods. Electron microscopy will detect the smallest fibres, which will constitute a large part of the surface, but less of the mass. The method used by Timbrell et $a l^{8}$ has not been proved to be effective for the smallest fibres. Wet digestion procedures are furthermore known to produce a loss of fibres, ${ }^{18}$ and from their report it is not possible to determine if variation in regional distribution of the fibres within the lung had been taken into account.

Another important point is the different clearance mechanisms of asbestos fibre types from the lung. Fibres of all types are certainly cleared from lung tissue over a period of years by physical movement and 
chemical dissolution. It is generally accepted that this applies more readily for chrysotile asbestos than for the amphiboles. In this case energy dispersive $x$ ray microanalysis of the fibres showed that more than $90 \%$ were amphibole fibres, mainly crocidolite, and less than $10 \%$ chrysotile which is consistent with earlier findings. ${ }^{9}$ This implies that if the correlation between fibre concentration and grade of fibrosis is real and related to the fibre number present in the tissue at necropsy it is probably related to the number of amphibole fibres which is consistent with the findings by Warnock et al. ${ }^{21}$

We are indebted to Mrs Randi Baunan, Mr Rune Hansen, Mrs Liv Overaae, and Mrs Elin Thorner for their skilful technical help.

Requests for reprints to: Dr B Gylseth, Institute of Occupational Health, PB 8149, Dep 0033 Oslo 1, Norway.

\section{References}

1 Wagner JC. The pneumoconioses due to mineral dusts. Journal of the Geological Society 1980;137:537-45.

2 Craighead JE. Asbestos-associated diseases. Arch Pathol Lab Med 1982;106:542-96.

3 Sebastien P, Fondimare A, Bignon J, Monchaux G, Desbordes J, Bonnaud G. Topographic distribution of asbestos fibres in human lung in relation to occupational and non-occupational exposure. In: Walton WH, ed. Inhaled particles IV. Oxford: Pergamon Press, 1977:435-46.

4 Ophus EM, Mowe G, Gylseth B. Scanning electron microscopy and $x$-ray microanalysis of mineral deposits in lungs of a patient with malignant mesothelioma. $\mathrm{Br} J$ Ind Med 1980;37:375-81.

5 Churg A, Wood P. Observations on the distribution of asbestos fibers in human lungs. Environ Res 1983;31:374-80.

6 Morgan A, Holmes A. Distribution and characteristics of amphibole asbestos fibres, measured with the light microscope, in the left lung of an insulation worker. Br J Ind Med 1983;40:45-50.
7 Gylseth B, Churg A, Davis JMG, et al. Analysis of asbestos fibers and asbestos bodies in human lung tissue samples. An international interlaboratory trial. Scand $J$ Work Environ Health 1985;11:107-10.

8 Timbrell V, Ashcroft T, Goldstein B, et al. Dose-response relationship for asbestosis. Presented at VI international symposium on inhaled particles, Cambridge 1985. Oxford: Pergamon Press (in press).

9 Gylseth B, Mowe G, Wannag A. Fibre type and concentration in the lungs of workers in an asbestos cement factory. $\mathrm{Br} J$ Ind Med 1983;40:375-9.

10 Craighead J, Abraham J, Churg A, et al. Pathology standards for diagnosis of asbestos related diseases. Arch Pathol Lab Med 1982;106:543-97.

11 Pooley FD, Clark NJ. Quantitative assessment of inorganic fibrous particulates in dust samples with an analytical transmission electron microscope. Ann Occup Hyg 1979;22:253-71.

12 Leidel NA, Busch KA, Lynch JR. Occupational exposure sampling strategy. Cincinnati: NIOSH (DHEW(NIOSH) publ No 77-173).

13 Ashcroft T, Heppleston AG. The optical and electron microscope determination of pulmonary asbestos fibre concentration and its relation to human pathological reaction. J Clin Pathol 1973;26:224-34.

14 Whitwell F, Scott J, Grimshaw M. Relationship between occupations and asbestos fibre content in the lungs in patients with pleural mesothelioma lung cancer and other diseases. Thorax 1977;32:377-86.

15 Morgan A, Holmes A. Concentrations and characteristics of amphibole fibres in the lungs of workers exposed to crocidolite in the British gas-mask factories, and elsewhere, during the second world war. Br J Ind Med 1982;39:62-9.

16 Jones JSP, Smith PG, Pooley FD, et al. The consequences of asbestos dust exposure in a wartime gas-mask factory. In: Wagner JC, ed. Biological effects of mineral fibres. Vol 2. Lyon: International Agency for Research on Cancer, 1980:637-53.

17 Gylseth B, Baunan RH. Topographic and size distribution of asbestos bodies in human lungs. Scand $J$ Work Environ Health 1981:7:190-5.

18 Gylseth B, Baunan RH, Overaae L. Analysis of fibres in human lung tissue. $\mathrm{Br} \mathrm{J}$ Ind $\mathrm{Med}$ 1982;39:191-5.

19 Davis JMG, Gylseth B, Morgan A. Assessment of mineral fibres from human lung tissue. Thorax 1986;41:167-75.

20 Rogers A. Determination of mineral fibre in human lung tissue by light microscopy and transmission electron microscopy. Ann Occup Hyg 1984;28:1-12.

21 Warnock MA, Kuwahara TJ, Wolery G. The relation of asbestos burden to asbestosis and lung cancer. Pathology Annual Part II 1983;18:109-45. 